\title{
Clinical, pathological and prognostic characteristics of gastroenteropancreatic neuroendocrine neoplasms in China: a retrospective study
}

\author{
Xianbin Zhang ${ }^{1 \dagger}$, Li Ma ${ }^{2 \dagger}$, Haidong Bao', Jing Zhang ${ }^{1}$, Zhongyu Wang ${ }^{1}$ and Peng Gong ${ }^{1 *}$
}

\begin{abstract}
Background: Gastroenteropancreatic neuroendocrine neoplasms (GEP-NENs) are rare neuroendocrine tumors, and lack of data in Asian populations especially in China. The aim of this retrospective study was to assess the clinical, pathological and prognostic characteristics of GEP-NENs in China.

Methods: We collected clinical and pathological data of 168 patients diagnosed with GEP-NENs and treated at the First and Second Affiliated Hospitals of Dalian Medical University between January 2003 and December 2012. Kaplan-Meier method and log rank analysis was used to analyze the prognostic significance of clinical and pathological characteristics.

Results: Mean age was $51.83 \pm 14.03$ and the male-to-female ratio was 1.5:1. Primary sites were the rectum (58.93\%), pancreas (13.69\%), stomach (9.52\%), duodenum (5.36\%), colon (4.76\%), appendix (4.76\%), ileum (2.38\%) and jejunum (0.60\%). Most patients (95.83\%) presented non-functional tumors with non-specific symptoms such as abdominal or back pain (29.17\%) and gastrointestinal bleeding (25.60\%). Based on the 2010 World Health Organization (WHO) classification, patients were diagnosed with neuroendocrine tumor (NET) (24.40\%) or neuroendocrine carcinoma (NEC) (7.14\%). The estimated mean survival was $8.94 \pm 0.28$ years (95\% Cl: 8.40-9.48). Male gender, young age, small tumor size and NET tumor type were favorable prognostic factors.

Conclusion: Chinese GEP-NENs patients present characteristics that are similar to American and European patients. However, there is an urgent need to establish a national database for understanding the clinical and epidemiological features of GEP-NENs in China.
\end{abstract}

Keywords: Neuroendocrine neoplasms, Carcinoma, Epidemiology, China

\section{Background}

Neuroendocrine neoplasms (NENs) are epithelial tumors with a predominant neuroendocrine differentiation, and they can develop in most organs. This fairly rare neoplasms displays a large spectrum of clinical presentations [1]. According to the Surveillance, Epidemiology and End results (SEER) database, more than half of all NENs are gastroenteropancreatic NENs (GEP-NENs) (61\%), with the highest frequency being observed in the rectum $(17.7 \%$ of

\footnotetext{
* Correspondence: gongpengdalian@163.com

${ }^{\dagger}$ Equal contributors

'Department of Hepatobiliary Surgery, the First Affiliated Hospital of Dalian Medical University, Zhongshan Road No. 222, Dalian 116011, Liaoning

Province, China

Full list of author information is available at the end of the article
}

NENs), small intestine (17.3\% of NENs) and colon (10.1\% of NENs), followed by the pancreas (7.0\%), stomach (6.0\%), and appendix (3.1\%) [2]. The annual incidence of GEP-NENs is about $3.65-4.7$ cases per 100,000 people in the United States (USA) [2,3]. African Americans show a higher incidence than Caucasians (6.46 vs. 4.60 per $100,000)$ [2]. The incidence is also slightly higher in men compared with women $(4.97$ vs. 4.49 per 100,000$)$ [2]. Similar rates were reported in Sweden, Norway, Spain and England [4-7].

None of the published nomenclatures and classifications of NENs present a unified classification that is accepted by clinicians and pathologists [8,9]. In 2010, the WHO presented a new classification of NENs, in which 
the term NENs describes all tumors with a neuroendocrine differentiation. GEP-NENs can be subdivided into two groups: the well-differentiated neuroendocrine tumors (NETs) and the poorly-differentiated neuroendocrine carcinomas (NECs) [10,11]. Furthermore, NETs and NECs are graded into three types, grades 1 (G1), 2 (G2) and 3 (G3), according to different definitions of proliferation using the mitotic count and/or the Ki-67 index [11]. In general, both G1 and G2 NENs are considered as NETs, and G3 NENs are considered as NECs [11].

Many studies reported the epidemiology, diagnosis, pathology and management of GEP-NENs in the American and the European populations $[2,8,12-14]$, but there is a lack of data in Asian populations, especially in China. Therefore, the objective of the present study was to perform an epidemiological study of GEP-NENs in a Chinese population. The present study might provide new clues about the development and the management of these rare tumors.

\section{Methods \\ Patients}

We performed a retrospective analysis of all patients diagnosed with GEP-NENs according to the WHO 2000 classification [15,16] between January 2003 and December 2012 at the First and Second Affiliated Hospitals of Dalian Medical University.

All patients included in the present study had to have received a pathological diagnosis of GEP-NENs, and the original pathology report had to be available. Patients were excluded if they had received a diagnosis of primary NENs of any other site, or if the primary NEN site was unknown. In addition, patients with incomplete records (clinical and pathological), who were lost to follow-up, or who refused to participate in our study were also excluded. The ethics committee of the First Affiliated Hospital of Dalian Medical University approved the study protocol (LCKY 2012-32).

\section{Data collection}

At the Dalian Medical University, all cancer cases are prospectively collected into a database. Therefore, the following variables were collected and analyzed: clinical characteristics (gender, age, symptoms, signs), diagnostic procedures (imagery, pathology), tumor characteristics (primary site, size, stage, grading, World Health Organization (WHO) 2010 classification, WHO 2000 classification), treatments (surgery, hepatic artery interventional chemotherapy, pharmacotherapy), and followup (date of diagnosis, date of death and cause of death).

Cancer staging was performed using the usual tumor node metastasis (TNM) approach according to the anatomical sites of the tumors [11,17]. Grading was based on morphological criteria and tumor proliferative activity.
Tumors with a Ki-67 index of $\leq 2 \%$ were classified as G1, $3-20 \%$ as G2, and $>20 \%$ as G3. Similarly, tumors with a mitotic rate of $<2$ per 10 high power fields (HPF) were classified as G1, 2-20/10 HPF as G2, and > 20/10 HPF as G3. GEP-NENs were further classified as NET (G1 and G2), or NEC (G3), according to the 2010 WHO classification $[10,11]$.

We performed the final follow-up by telephone, mail or outpatient department visit in December 2012.

\section{Statistical analysis}

All statistical analyses were performed using SPSS 20.0 for Windows (IBM Corporation. Armonk, NY, USA). We tested continuous variables for normal distribution. Normally distributed continuous variables are expressed as mean and standard deviation, and were analyzed using independent samples $t$-tests. Categorical variables are expressed as frequencies and proportions, and were analyzed using the chi-square test or Fisher's exact test, as appropriate. We used the Kaplan-Meier method for survival analysis, log-rank tests were used for comparision among groups and post hoc analysis for pairwise comparisons between groups. We performed Cox proportional hazards model to identify independent factors associated with prognosis. The level of significance was set at $P<0.05$.

\section{Results}

\section{Patients' clinical characteristics}

One hundred-sixty-eight patients were included in the present study. All were Han Chinese and Dalian natives; $102(61.00 \%)$ patients were male, 66 (39.00\%) female, and the male-to-female ratio was $1.5: 1$. Mean age was $51.83 \pm$ 14.03. The most frequent initial symptoms and signs were abdominal or back pain $(\mathrm{n}=49,29.17 \%)$, followed by gastrointestinal bleeding $(\mathrm{n}=43,25.60 \%)$, dyspepsia $(\mathrm{n}=$ $24,14.29 \%)$, and diarrhea $(\mathrm{n}=21,12.50 \%)$ (Table 1). Eight $(4.76 \%)$ cases were incidental findings during routine health examinations; these patients were asymptomatic. Seven $(4.16 \%)$ patients received a diagnosis of functional tumors: all of these were insulinomas, and the patients were hypoglycemic.

\section{Diagnostic procedures}

The following procedures were performed at least once during the diagnosis and management of these tumors: endoscopy ( $\mathrm{n}=133,79.17 \%)$, ultrasound $(\mathrm{n}=82,48.81 \%)$, computed tomography (CT) scan $(\mathrm{n}=96,57.14 \%)$, and magnetic resonance imaging (MRI) $(\mathrm{n}=17,10.12 \%)$. The highest positive rate was $97.74 \%$ (130/133) for endoscopy, followed by endoscopic ultrasound (90.00\%), MRI (70.59\%), ultrasound (58.54\%), and CT (54.17\%). Positron emission computed tomography imaging using $\left({ }^{18} \mathrm{~F}\right)$-fluoro-deoxy-glucose as tracer $\left({ }^{18} \mathrm{~F}\right.$-FDG-PET) was 
Table 1 Patients' characteristics

\begin{tabular}{|c|c|c|c|c|}
\hline & Male & Female & Total & $P$-value \\
\hline N (\%) & $102(61.00)$ & $66(39.00)$ & $168(100.00)$ & \\
\hline Age (years) & $52.91 \pm 13.65$ & $50.15 \pm 14.56$ & $51.83 \pm 14.03$ & 0.06 \\
\hline \multicolumn{5}{|l|}{ Primary tumor site } \\
\hline Gastrointestinal tract & $93(55.36)$ & $52(30.95)$ & $145(86.31)$ & $0.02^{*}$ \\
\hline Stomach & $12(7.14)$ & $4(2.38)$ & $16(9.52)$ & 0.22 \\
\hline Duodenum & $6(3.57)$ & $3(1.79)$ & $9(5.36)$ & 1.00 \\
\hline Jejunum & $1(0.60)$ & $0(0.0)$ & $1(0.60)$ & 1.00 \\
\hline Ileum & $3(1.79)$ & $1(0.60)$ & $4(2.38)$ & 1.00 \\
\hline Colon & $6(3.57)$ & $2(1.19)$ & $8(4.76)$ & 0.48 \\
\hline Appendix & $4(2.38)$ & $4(2.38)$ & $8(4.76)$ & 0.71 \\
\hline Rectum & $61(36.31)$ & $38(22.62)$ & 99 (58.93) & 0.74 \\
\hline Pancreas & $9(5.36)$ & $14(8.33)$ & $23(13.69)$ & $0.02^{*}$ \\
\hline \multicolumn{5}{|l|}{ Clinical Symptoms } \\
\hline Abdominal or back pain & $27(16.07)$ & $22(13.10)$ & $49(29.17)$ & 0.33 \\
\hline Gastrointestinal bleeding $^{a}$ & $28(16.67)$ & $15(8.93)$ & $43(25.60)$ & 0.49 \\
\hline Dyspepsia $^{b}$ & $16(9.52)$ & $8(4.76)$ & $24(14.29)$ & 0.52 \\
\hline Diarrhea & $18(10.71)$ & $3(1.79)$ & $21(12.50)$ & 0.12 \\
\hline Tenesmus & $13(7.74)$ & $6(3.57)$ & 19 (11.31) & 0.47 \\
\hline Appetite loss & $11(6.55)$ & $7(4.17)$ & 18 (10.71) & 0.97 \\
\hline Constipation & $3(1.79)$ & $5(2.98)$ & $8(4.76)$ & 0.27 \\
\hline Hypoglycemia $^{c}$ & $5(2.98)$ & $2(1.19)$ & $7(4.17)$ & 0.71 \\
\hline Weight loss & $4(2.38)$ & $1(0.60)$ & $5(2.98)$ & 0.65 \\
\hline Asthenia & $1(0.60)$ & $1(0.60)$ & $2(1.19)$ & 1.00 \\
\hline Dysphagia & $1(0.60)$ & $0(0)$ & $1(0.60)$ & 1.00 \\
\hline \multicolumn{5}{|l|}{ Main Signs } \\
\hline Abdominal mass & $2(1.19)$ & $2(1.19)$ & $4(2.38)$ & 0.65 \\
\hline Jaundice $^{\mathrm{d}}$ & $1(0.60)$ & $1(0.60)$ & $2(1.19)$ & 1.00 \\
\hline Rash & $1(0.60)$ & $2(1.19)$ & $3(1.79)$ & 0.56 \\
\hline
\end{tabular}

${ }^{a}$ fecal occult blood, bloody stool, hematemesis.

bfullness, bloating, belching, nausea, vomiting.

tremors, cold sweats, palpitations, hunger, irritability, headache, dizziness, blurred vision, disorientation, coma or seizures.

${ }^{d}$ skin or sclera.

performed in four patients, and detected the lesion in three of them, showing a detection rate of $75.00 \%$. Chromogranin A, synaptophysin and neuronspecific enolase (NSE) are general neuroendocrine markers [18], and were positive in $72.62 \%, 76.19 \%, 32.74 \%$ of patients, respectively (Table 2).

\section{Tumors' characteristics}

As listed in Table 1 , the rectum $(\mathrm{n}=99,58.93 \%)$ was the most frequent primary site, followed by the pancreas $(\mathrm{n}=$ 23, 13.69\%), stomach $(\mathrm{n}=16,9.52 \%)$, duodenum $(\mathrm{n}=9$, $5.36 \%)$, colon $(\mathrm{n}=8,4.76 \%)$, appendix $(\mathrm{n}=8,4.76 \%)$, ileum $(\mathrm{n}=4,2.38 \%)$, and jejunum $(\mathrm{n}=1,0.60 \%)$. There was gender difference in primary tumor site (Table 1 ).
According to the pathology reports of the 168 tumors, 23 specimens were too small to be properly described (tumor size or extension). The mean size (longest diameter) of the remaining 145 tumors was $2.4 \pm 2.3 \mathrm{~cm}$.

At diagnosis, tumor spread was local in $64.29 \%(n=108)$ of patients, loco-regional in $14.29 \%(\mathrm{n}=24)$, and metastatic in $8.33 \%(\mathrm{n}=14)($ Table 3$)$. The most common site of distant metastases was the liver (11/14, 78.57\%), followed by the peritoneum $(n=2)$, and bones $(n=1)$. Two patients presented metastatic tumors in the liver accompanied with brain $(\mathrm{n}=1)$ or ovary $(\mathrm{n}=1)$ metastases. According to the 2000 WHO classification, 7.14\% of GEP-NENs ( $\mathrm{n}=$ 12) were classified as well-differentiated endocrine tumors, $4.17 \%(\mathrm{n}=7)$ were classified as well-differentiated 
Table 2 Diagnostic procedures

\begin{tabular}{lcc}
\hline & Cases tested, N (\%) & Positive, N (\%) \\
\hline Imaging diagnosis & $133(79.17)$ & $130(97.74)$ \\
Endoscopy & $26(15.48)$ & $26(100.00)$ \\
$\quad$ Gastroscopy & $11(6.55)$ & $8(72.73)$ \\
$\quad$ Small intestinal endoscopy & $96(57.14)$ & $96(100.00)$ \\
Proctoscopy & $82(48.81)$ & $48(58.54)$ \\
Eltrasound & $20(11.90)$ & $18(90.00)$ \\
CT & $96(57.14)$ & $52(54.17)$ \\
MRI & $17(10.12)$ & $12(70.59)$ \\
PET-CT & $4(2.38)$ & $3(75.00)$ \\
Immunohistochemistry & & $122(72.62)$ \\
Chromogranin A & $168(100)$ & $128(76.19)$ \\
Synaptophysin & $168(100)$ & $55(32.74)$ \\
NSE & $168(100)$ &
\end{tabular}

$\mathrm{CT}$, computed tomography scan; MRI, magnetic resonance imaging; PET-CT, positron emission computed tomography; NSE, neuron-specific enolase. endocrine carcinomas, and 7.74\% $(\mathrm{n}=13)$ were classified as poorly differentiated endocrine carcinomas. Mitotic rates were missing in all pathology reports. Most reports $(\mathrm{n}=$ 115) did not present morphological criteria and the Ki-67 index. According to the available Ki-67 indexes, $20.23 \%$ of tumors were G1, $4.17 \%$ were G2, and $7.14 \%$ were G3. The most common tumor type was NET $(n=41)$, followed by NEC $(n=12)$ (Table 3).

\section{Treatment}

Table 4 presents the treatment modalities: $86.90 \%$ of patients underwent surgery. The surgical approach in each patient was the most optimal one, tailored to each patient's disease. Sixteen patients underwent conversion to radical resection after endoscopic resection. Seven patients had postoperative complications (intestinal fistula, seroperitoneum, anastomotic stricture, intestinal obstruction, incision fat necrosis, and anastomotic fistula), and five patients had to be reoperated for their complications.

Only $1.79 \%(n=3)$ of patients underwent hepatic transcatheter arterial chemoembolization (TACE) to treat liver

Table 3 Tumors' characteristics

\begin{tabular}{|c|c|c|c|c|c|c|c|c|c|}
\hline & $\begin{array}{l}\text { Stomach } \\
n=16\end{array}$ & $\begin{array}{l}\text { Duodenum } \\
\mathrm{n}=9\end{array}$ & $\begin{array}{l}\text { Jejunum } \\
n=1\end{array}$ & $\begin{array}{l}\text { Ileum } \\
n=4\end{array}$ & $\begin{array}{l}\text { Colon } \\
n=8\end{array}$ & $\begin{array}{l}\text { Appendix } \\
n=8\end{array}$ & $\begin{array}{l}\text { Rectum } \\
\mathrm{n}=99\end{array}$ & $\begin{array}{l}\text { Pancreas } \\
n=23\end{array}$ & $\begin{array}{l}\text { Total } \\
\mathrm{N}=168 \text { (\%) }\end{array}$ \\
\hline \multicolumn{10}{|l|}{ Size } \\
\hline$<1 \mathrm{~cm}$ & 2 & 0 & 0 & 0 & 1 & 0 & 39 & 2 & 44 (26.19) \\
\hline $1-2 \mathrm{~cm}$ & 1 & 4 & 0 & 2 & 1 & 3 & 31 & 8 & $50(29.76)$ \\
\hline$>2 \mathrm{~cm}$ & 9 & 5 & 1 & 2 & 5 & 1 & 15 & 13 & $51(30.36)$ \\
\hline Unclear & 4 & 0 & 0 & 0 & 1 & 4 & 14 & 0 & 23 (13.69) \\
\hline \multicolumn{10}{|l|}{ Stage } \\
\hline $\mathrm{T}_{1} \mathrm{~N}_{0} \mathrm{M}_{0}$ & 4 & 0 & 0 & 0 & 1 & 2 & 43 & 5 & 55 (32.74) \\
\hline $\mathrm{T}_{2} \mathrm{~N}_{0} \mathrm{M}_{0}$ & 1 & 3 & 0 & 0 & 0 & 1 & 17 & 5 & $27(16.07)$ \\
\hline $\mathrm{T}_{3} \mathrm{~N}_{0} \mathrm{M}_{0}$ & 2 & 1 & 0 & 1 & 2 & 4 & 2 & 7 & $19(11.31)$ \\
\hline $\mathrm{T}_{4} \mathrm{~N}_{0} \mathrm{M}_{0}$ & 1 & 2 & 0 & 0 & 0 & 0 & 0 & 4 & $7(4.17)$ \\
\hline $\mathrm{T}_{\text {any }} \mathrm{N}_{1} \mathrm{M}_{0}$ & 5 & 1 & 1 & 3 & 3 & 0 & 10 & 1 & $24(14.29)$ \\
\hline $\mathrm{T}_{\text {any }} \mathrm{N}_{\text {any }} \mathrm{M}_{1}$ & 2 & 2 & 0 & 0 & 2 & 1 & 6 & 1 & $14(7.74)$ \\
\hline Unclear & 1 & 0 & 0 & 0 & 0 & 0 & 21 & 0 & $22(13.69)$ \\
\hline \multicolumn{10}{|l|}{ WHO 2010} \\
\hline NET/G1 & 0 & 2 & 0 & 0 & 1 & 0 & 26 & 5 & $34(20.23)$ \\
\hline NET/G2 & 0 & 1 & 0 & 0 & 1 & 0 & 3 & 2 & $7(4.17)$ \\
\hline NEC/G3 & 1 & 0 & 0 & 0 & 2 & 0 & 4 & 5 & $12(7.14)$ \\
\hline Unclear & 15 & 6 & 1 & 4 & 4 & 8 & 66 & 11 & 115 (68.45) \\
\hline \multicolumn{10}{|l|}{ WHO 2000} \\
\hline WDET & 0 & 2 & 1 & 0 & 0 & 0 & 5 & 4 & $12(7.14)$ \\
\hline WDEC & 0 & 2 & 0 & 0 & 0 & 0 & 5 & 0 & $7(4.17)$ \\
\hline PDEC & 1 & 2 & 0 & 0 & 0 & 0 & 4 & 6 & $13(7.74)$ \\
\hline Unclear & 15 & 3 & 0 & 4 & 8 & 8 & 85 & 13 & 136 (80.95) \\
\hline
\end{tabular}

TNM: tumor-node-metastasis approach [11]; NET, neuroendocrine tumor; NEC, neuroendocrine carcinoma; G1, grade 1; G2, grade 2; G3, grade 3; WDET, well differentiated endocrine tumour; WDEC, well differentiated endocrine carcinoma; PDEC, poorly differentiated endocrine carcinoma. 
Table 4 Treatment modalities

\begin{tabular}{|c|c|c|c|c|}
\hline & Male & Female & Total & $P-$ \\
\hline & $N=102$ & $N=66$ & $N=168$ & \\
\hline Surgery & $89(52.98)$ & 57 (33.93) & $146(86.90)$ & 0.87 \\
\hline Laparotomy & $69(41.07)$ & $36(21.43)$ & $105(62.50)$ & 0.09 \\
\hline Laparoscopic & $3(1.79)$ & $1(0.60)$ & $4(2.38)$ & 1.00 \\
\hline Endoscopic & $17(10.12)$ & $20(11.90)$ & $37(22.02)$ & 0.04 \\
\hline TACE & $2(1.19)$ & $1(0.60)$ & $3(1.79)$ & 1.00 \\
\hline \multicolumn{5}{|c|}{ Pharmacotherapy } \\
\hline Chemotherapy & $14(8.33)$ & $4(2.38)$ & $18(10.71)$ & 0.12 \\
\hline Octreotide & $12(7.14)$ & $12(7.14)$ & $24(14.29)$ & 0.25 \\
\hline
\end{tabular}

TACE, transcatheter arterial chemoembolization.

metastases. Chemotherapy was the only intervention treatment in five patients with inoperable tumors, and 13 patients underwent chemotherapy as postoperative adjuvant therapy (Table 4). The most commonly used regimen was FOLFOX4 (oxaliplatin, leucovorin and 5-fluorouracil, $\mathrm{n}=7$ ), followed by oxaliplatin and capecitabine $(n=5)$, oxaliplatin and fluoropyrimidine $(\mathrm{n}=1)$, paclitaxel and carboplatin $(\mathrm{n}=1)$, docetaxel and gemcitabine $(\mathrm{n}=1)$, cisplatin and 5-fluorouracil $(\mathrm{n}=1)$, streptozotocin and 5-fluorouracil $(\mathrm{n}=1)$, and taxane and platinum $(\mathrm{n}=1)$. Twenty-four patients (14.29\%) received octreotide, a somatostatin analogue, as a biological therapy combined with surgery or chemotherapy. Except for endoscopic therapy, the treatment modality distribution showed no difference in gender for any other therapies.

\section{Follow-up}

The median follow-up was 2.67 years (range: 0.0110.00 years). Because of the short follow-up period, the GEP-NENs' median survival time was not attained during the study. At the last follow-up, 14 patients had died from their GEP-NENs, and 16 patients had died from accidents or other diseases (cerebral thrombosis, lung cancer, myocardial infarction, etc.). The estimated mean overall survival was $8.94 \pm 0.28$ years (95\% confidence interval (CI): 8.40-9.48). We analyzed potential independent survival factors, such as age, gender, primary tumor site, tumor size, and tumor type (NET or NEC). As shown in Table 5, survival was significantly better in young patients, male patients, patients with small tumor and the NET subtype (Figure 1). Multivariate

\section{Table 5 Overall survival}

\begin{tabular}{|c|c|c|c|c|c|}
\hline & Number & Mean survival times (years) & $95 \% \mathrm{Cl}$ & $x^{2}$ & $P$-value \\
\hline All & 168 & $8.94 \pm 0.28$ & $8.40-9.48$ & & \\
\hline Age & & & & 4.33 & $0.04^{*}$ \\
\hline$\leq 50$ & 76 & $9.50 \pm 0.29$ & $8.92-10.07$ & & \\
\hline$>50$ & 92 & $7.46 \pm 0.38$ & $6.73-8.20$ & & \\
\hline Gender & & & & 4.25 & $0.04^{*}$ \\
\hline Male & 102 & $9.31 \pm 0.27$ & 8.78-9.84 & & \\
\hline Female & 66 & $7.71 \pm 0.61$ & $6.52-8.91$ & & \\
\hline Site & & & & 4.40 & 0.11 \\
\hline Rectum & 99 & $9.40 \pm 0.27$ & 8.88-9.92 & & \\
\hline Pancreas & 23 & $4.09 \pm 0.48$ & $3.14-5.03$ & & \\
\hline Others $^{a}$ & 46 & $7.59 \pm 0.57$ & $6.47-8.72$ & & \\
\hline Size & & & & 18.485 & $<0.01^{*}$ \\
\hline$<1 \mathrm{~cm}$ & 44 & $9.84 \pm 0.16$ & $9.53-10.15$ & & $<0.01^{\mathrm{c}}$ \\
\hline $1-2 \mathrm{~cm}$ & 50 & $8.88 \pm 0.28$ & $8.34-9.42$ & & $0.01^{c}$ \\
\hline$>2 \mathrm{~cm}$ & 51 & $5.06 \pm 0.51$ & 4.07-6.06 & & \\
\hline Unclear $^{\mathrm{b}}$ & 23 & $8.50 \pm 0.39$ & $7.74-9.26$ & & $0.01^{c}$ \\
\hline Tumor type & & & & 58.840 & $<0.01^{*}$ \\
\hline NET & 41 & $7.35 \pm 0.63$ & $6.13-8.58$ & & $<0.01^{c}$ \\
\hline NEC & 12 & $2.80 \pm 0.87$ & $1.09-4.50$ & & \\
\hline Unclear & 115 & $9.80 \pm 0.14$ & $9.53-10.08$ & & \\
\hline
\end{tabular}

athers represent stomach, duodenum, jejunum, ileum, colon, appendix.

${ }^{b}$ specimens too small to be properly described tumor size.

'log-rank test (pairwise over strata) according to size and tumor type; the $P$-values of tumor size $1 \mathrm{~cm}$ vs. $>2 \mathrm{~cm}, 1-2 \mathrm{~cm}$ vs. $>2 \mathrm{~cm}$, Unclear vs. $>2 \mathrm{~cm}$ and NET vs. NEC were $<0.05$.

${ }^{*} P<0.05$.

NET, neuroendocrine tumor; NEC, neuroendocrine carcinoma. 
analysis confirmed that age and tumor type were the only independent prognostic factors for overall survival (Table 6).

\section{Discussion}

The aim of this retrospective study was to assess the clinical, pathological and prognosis characteristics of GEPNENs in China. The rectum, pancreas, stomach and duodenum were the most frequent primary sites. The majority of patients presented non-functional tumors with nonspecific symptoms such as abdominal or back pain and gastrointestinal bleeding. Based on the $2010 \mathrm{WHO}$ classification, most patients suffered from NET. The estimated mean survival was relatively short, with $8.94 \pm$ 0.28 years (95\% CI: 8.40-9.48). Male gender, young age, small tumor and NET tumor type were favorable prognostic factors.

NENs may develop anywhere in the body, but most of them do in the gastrointestinal tract [1]. A large-scale analysis of GEP-NENs $(n=29,664)$ from the SEER database revealed that the highest GEP-NENs frequency was in the rectum, followed by the small intestine, colon, pancreas, stomach, and appendix, and that the incidence increased with years at all primary sites, especially in the rectum and small intestine [3]. Similarly, we observed that the rectum
Table 6 Multivariate Cox proportional hazards model

\begin{tabular}{cccc}
\hline Variable & Hazard ratio & $\mathbf{9 5 \% ~ C l}$ & $\boldsymbol{P}$-value \\
\hline Age & 2.01 & $1.14-3.56$ & $0.02^{*}$ \\
Site & 2.94 & $0.82-10.53$ & 0.10 \\
Size & 3.55 & $0.82-15.47$ & 0.09 \\
Tumor type & 2.10 & $1.02-4.31$ & $0.04^{*}$ \\
\hline
\end{tabular}

${ }^{*} P<0.05$.

was the most frequent site of GEP-NENs, followed by the pancreas, and stomach; however, the small intestine only accounted for a small proportion of our cases. Nevertheless, primary tumor site distribution in the present study was similar to that of the Korean and Japanese populations $[13,19]$, suggesting that the distribution of GEPNENs' primary sites may be different between the Asian and the American populations. However, these observations might not reflect the true situation. Indeed, guidelines recommend that patients over 50 years undergo colonoscopy when they receive health check at our institutions, which should increase the early diagnosis rate of the disease. Meanwhile, with diagnostic improvements, more and more patients received a diagnosis of appendix NEN because of an incidental finding of the surgery for an

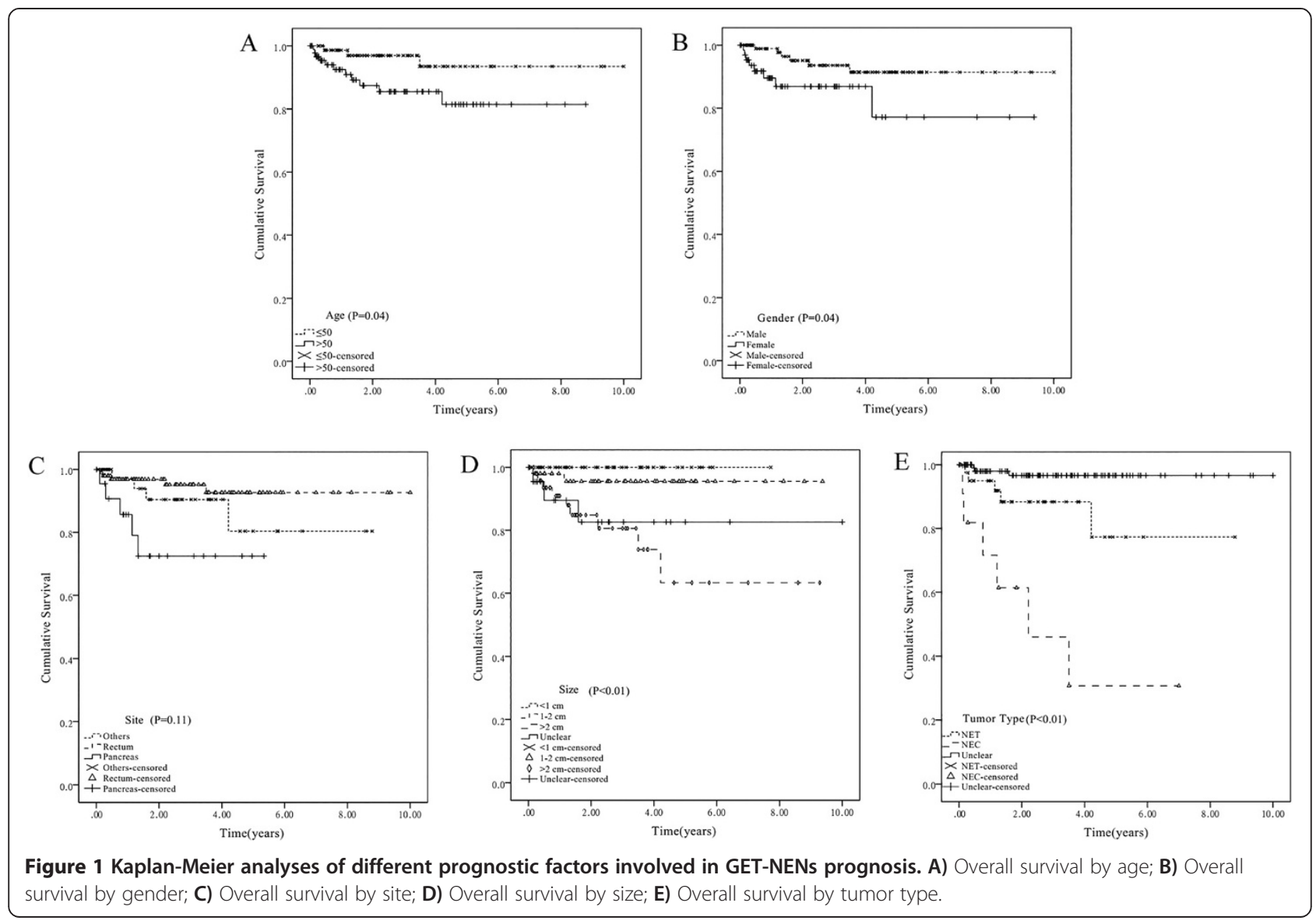


acute appendicitis. All of these might create a false impression that the incidence of GEP-NENs is increasing.

NENs can be classified into functional or nonfunctional tumors according to the symptoms associated with peptides and hormones overproduction [20]. The present study showed that most GEP-NENs in the Chinese population were nonfunctional tumors. Carcinoid syndrome, ZollingerEllison syndrome, Whipple triad, Verner-Morrison syndrome and glucagonoma syndrome are typical symptoms of functional NENs [21], but no patient showed these symptoms in the present study. This might be due to two reasons: 1) clinicians may not pay enough attention to these symptoms; or 2) NENs were diagnosed at the early stages, before being symptomatic.

The lack of a uniform nomenclature and classification system of GEP-NENs prevent the physicians from diagnosing and treating these tumors. The WHO updated its classification in 2010 and accepted the term "GEP-NENs" [22]. We reviewed the diagnosis process in our participating institutions. Unfortunately, but as expected, it was not standardized. The "gold standard" in our participating institutions was the use of general neuroendocrine markers, such as chromogranin A, synaptophysin or NSE [23]. We reviewed the pathology reports of our patients according to the new WHO 2010 diagnosis and classification criteria, and we observed that $24.40 \%$ patients suffered from NET $(n=41)$ and $7.14 \%$ from NEC $(n=12)$. Fourteen patients presented metastases at diagnosis. The total metastasis rate was $8.33 \%$, which was lower than what was previously reported [24]. The reasons may be responsible for regional difference. Unlike other solid tumors, there is a wide array of therapeutic options, such as surgery, interventional radiology, systemic therapy, somatostatin analogues, interferon, peptide-receptor radionuclide therapy, chemotherapy, and targeted agents (sunitinib, everolimus, bevacizumab) to palliate symptoms and extend survival in patients with GEP-NENs [25]. As for other tumors, surgery is an essential treatment in many GEP-NENs and is usually the only way to cure patients. The extent of surgical resection depends on the extent of the disease (local, regional or distant metastases). Cytoreductive surgery is recommended for palliation and to increase survival for patients with advanced disease [26]. In the present study, most patients underwent surgery, and only two patients who underwent surgery died during follow-up.

Chemotherapy is the first treatment option for inoperable or metastatic GEP-NENs. The cisplatin and etoposide combination is the most widely used chemotherapy regimen for GEP-NENs [27]. In our cohort, 18 patients received chemotherapy. The most frequently used chemotherapy regimen was the oxaliplatin, leucovorin and 5fluorouracil combination.

More and more studies report that biological and targeted therapies show great promises against NENs. Somatostatin analogues can reduce the hormone-related symptoms, and they are an effective therapeutic option for functional neuroendocrine tumors [28]. Sunitinib and everolimus may be used for patients with inoperable locally advanced or metastatic, progressive, well differentiated pancreatic NENs $[2,29,30]$. In the present study, 24 patients underwent somatostatin analogues treatment, seven of them suffering from functional tumors (insulinoma).

The present study suffered from some limitations. The population's characteristics (age and gender) presented in our study are similar to those reported in other studies of Asian populations [13,19,24,31,32]. However, they are different from those previously published using the SEER database or European populations $[12,14,33]$. Selection biases among races, populations and hospitals may be responsible for these differences. Second, the follow-up of the present study did not reach the median survival time previously reported. Indeed, our mean survival was $8.94 \pm$ 0.28 years, and was shorter than the 9.5 years reported by other investigators [24]. This is due to a short follow-up time and to the slow growing rate of the disease. Third, the small sample size might have been responsible for some bias in the multivariate and prognosis analyses. Fourth, the retrospective nature of the study prevented us from obtaining some information, such as the Ki-67 index. In addition, our follow-up system only contains data about the vital status (alive or not), and not about progression, preventing us to determine the progression-free survival. Finally, tumors in the rectum are more easily found at their early stages by endoscopic examination, while tumors at other sites (e.g. in the pancreas) necessitate examinations that are not routinely performed, which might affect the incidence.

\section{Conclusion}

In our study, non-specific clinical symptoms were the most common symptoms in patients with GEP-NENs. Diagnosis was mainly based on clinical manifestation, endoscopy and imagery, as well as on pathology. However, the recommended morphological criteria and proliferative activity of the tumor were not commonly used in pathological diagnosis. Surgery was the most common intervention. Male gender, young age ( $\leq 50$ years), tumor size $(<2 \mathrm{~cm})$ and NET diagnosis might be favorable prognostic factors. A national database of GEP-NENs should be established for studying the clinical and epidemiological features of these tumors, and to help physicians taking better clinical decisions.

\section{Consent}

Written informed consents were obtained from the patient for the publication of this report and any accompanying images. 


\section{Competing interests}

All authors declare that they have no competing interests.

\section{Authors' contribution}

$X Z$ : conception and design, acquisition of data, writing the manuscript. LM: analysis and interpretation of data. HB: acquisition of data. JZ: acquisition of data, analysis and interpretation of data. ZW: acquisition of data. PG: revising the manuscript. All authors read and approved the final manuscript.

\section{Acknowledgements}

This study was funded by the Specialized Research Fund for the Doctoral Program of Higher Education (No. 20122105110009) and the China National Natural Science Foundation (No.81200989). The funders had no role in study design, data collection and analysis, decision to publish, or preparation of the manuscript.

\section{Author details}

${ }^{1}$ Department of Hepatobiliary Surgery, the First Affiliated Hospital of Dalian Medical University, Zhongshan Road No. 222, Dalian 116011, Liaoning Province, China. ${ }^{2}$ Department of Epidemiology, Dalian Medical University, Dalian 116044, Liaoning Province, China.

Received: 30 December 2013 Accepted: 26 June 2014 Published: 8 July 2014

\section{References}

1. Modlin IM, Oberg K, Chung DC, Jensen RT, de Herder WW, Thakker RV, Caplin M, Delle Fave G, Kaltsas GA, Krenning EP, Moss SF, Nilsson O, Rindi G, Salazar R, Ruszniewski P, Sundin A: Gastroenteropancreatic neuroendocrine tumours. Lancet Oncol 2008, 9(1):61-72.

2. Yao JC, Hassan M, Phan A, Dagohoy C, Leary C, Mares JE, Abdalla EK, Fleming JB, Vauthey JN, Rashid A, Evans DB: One hundred years after "carcinoid": epidemiology of and prognostic factors for neuroendocrine tumors in 35,825 cases in the United States. J Clin Oncol 2008, 26(18):3063-3072.

3. Lawrence B, Gustafsson BI, Chan A, Svejda B, Kidd M, Modlin IM: The epidemiology of gastroenteropancreatic neuroendocrine tumors. Endocrinol Metab Clin North Am 2011, 40(1):1-18. vii.

4. Hemminki K, Li X: Incidence trends and risk factors of carcinoid tumors: a nationwide epidemiologic study from Sweden. Cancer 2001, 92(8):2204-2210.

5. Hauso O, Gustafsson BI, Kidd M, Waldum HL, Drozdov I, Chan AK, Modlin IM: Neuroendocrine tumor epidemiology: contrasting Norway and North America. Cancer 2008, 113(10):2655-2664.

6. Ploeckinger U, Kloeppel G, Wiedenmann B, Lohmann R, representatives of 21 German NETC: The German NET-registry: an audit on the diagnosis and therapy of neuroendocrine tumors. Neuroendocrinology 2009, 90(4):349-363.

7. Lepage C, Rachet B, Coleman MP: Survival from malignant digestive endocrine tumors in England and Wales: a population-based study. Gastroenterology 2007, 132(3):899-904.

8. Pape UF, Jann H, Muller-Nordhorn J, Bockelbrink A, Berndt U, Willich SN, Koch M, Rocken C, Rindi G, Wiedenmann B: Prognostic relevance of a novel TNM classification system for upper gastroenteropancreatic neuroendocrine tumors. Cancer 2008, 113(2):256-265.

9. Kloppel G, Rindi G, Perren A, Komminoth P, Klimstra DS: The ENETS and AJCC/UICC TNM classifications of the neuroendocrine tumors of the gastrointestinal tract and the pancreas: a statement. Virchows Arch 2010, 456(6):595-597.

10. Bosman FT, Carneiro F, Hruban RH, Theise ND: WHO classification of tumours of the digestive system. 4th edition. Lyon: International Agency for Research on Cancer; 2010.

11. Bosman FT, Carneiro F, Hruban RH, Theise ND: WHO classification of tumours of the digestive system. Geneva, Switzerland: World Health Organization; 2010.

12. Niederle MB, Hackl M, Kaserer K, Niederle B: Gastroenteropancreatic neuroendocrine tumours: the current incidence and staging based on the WHO and European Neuroendocrine Tumour Society classification: an analysis based on prospectively collected parameters. Endocr Relat Cancer 2010, 17(4):909-918.
13. Ito T, Sasano H, Tanaka M, Osamura RY, Sasaki I, Kimura W, Takano K, Obara T, Ishibashi M, Nakao K, Doi R, Shimatsu A, Nishida T, Komoto I, Hirata Y, Nakamura K, Igarashi H, Jensen RT, Wiedenmann B, Imamura M: Epidemiological study of gastroenteropancreatic neuroendocrine tumors in Japan. J Gastroenterol 2010, 45(2):234-243.

14. Garcia-Carbonero R, Capdevila J, Crespo-Herrero G, Diaz-Perez JA, Martinez Del Prado MP, Alonso Orduna V, Sevilla-Garcia I, Villabona-Artero C, Beguiristain-Gomez A, Llanos-Munoz M, Marazuela M, Alvarez-Escola C, Castellano D, Vilar E, Jimenez-Fonseca P, Teule A, Sastre-Valera J, Benavent-Vinuelas M, Monleon A, Salazar R: Incidence, patterns of care and prognostic factors for outcome of gastroenteropancreatic neuroendocrine tumors (GEP-NETs): results from the National Cancer Registry of Spain (RGETNE). Ann Oncol 2010, 21(9):1794-1803.

15. KLÖPPEL G, PERREN A, HEITZ PU: The gastroenteropancreatic neuroendocrine cell system and its tumors: the WHO classification. Ann N Y Acad Sci 2004, 1014(1):13-27.

16. Niederle MB, Niederle B: Diagnosis and treatment of gastroenteropancreatic neuroendocrine tumors: current data on a prospectively collected, retrospectively analyzed clinical multicenter investigation. Oncologist 2011, 16(5):602-613.

17. Oberg K: Diagnostic work-up of gastroenteropancreatic neuroendocrine tumors. Clinics (Sao Paulo) 2012, 67(Suppl 1):109-112.

18. Strosberg JR, Nasir A, Hodul P, Kvols L: Biology and treatment of metastatic gastrointestinal neuroendocrine tumors. Gastrointest Cancer Res 2008, 2(3):113-125.

19. Gastrointestinal Pathology Study Group of Korean Society of P, Cho MY, Kim JM, Sohn JH, Kim MJ, Kim KM, Kim WH, Kim H, Kook MC, Park do Y, Lee JH, Chang H, Jung ES, Kim HK, Jin SY, Choi JH, Gu MJ, Kim S, Kang MS, Cho CH, Park MI, Kang YK, Kim YW, Yoon SO, Bae HI, Joo M, Moon WS, Kang DY, Chang SJ: Current Trends of the Incidence and Pathological Diagnosis of Gastroenteropancreatic Neuroendocrine Tumors (GEP-NETs) in Korea 2000-2009: Multicenter Study. Cancer Res Treat 2012, 44(3):157-165.

20. Metz DC, Jensen RT: Gastrointestinal neuroendocrine tumors: pancreatic endocrine tumors. Gastroenterology 2008, 135(5):1469-1492.

21. Oberg K, Akerstrom G, Rindi G, Jelic S, Group EGW: Neuroendocrine gastroenteropancreatic tumours: ESMO Clinical Practice Guidelines for diagnosis, treatment and follow-up. Ann Oncol 2010, 21(Suppl 5):v223-227.

22. Stoyianni A, Pentheroudakis G, Pavlidis N: Neuroendocrine carcinoma of unknown primary: a systematic review of the literature and a comparative study with other neuroendocrine tumors. Cancer Treat Rev 2011, 37(5):358-365.

23. Kuiper P, Verspaget HW, Overbeek LI, Biemond I, Lamers CB: An overview of the current diagnosis and recent developments in neuroendocrine tumours of the gastroenteropancreatic tract: the diagnostic approach. Neth J Med 2011, 69(1):14-20.

24. Wang $Y H$, Lin $Y, X$ Xue L, Wang JH, Chen MH, Chen J: Relationship between clinical characteristics and survival of gastroenteropancreatic neuroendocrine neoplasms: A single-institution analysis (1995-2012) in South China. BMC Endocr Disord 2012, 12:30.

25. Ramage JK, Ahmed A, Ardill J, Bax N, Breen DJ, Caplin ME, Corrie P, Davar J, Davies AH, Lewington V, Meyer T, Newell-Price J, Poston G, Reed N, Rockall A, Steward W, Thakker RV, Toubanakis C, Valle J, Verbeke C, Grossman AB, Uk, Ireland Neuroendocrine Tumour S: Guidelines for the management of gastroenteropancreatic neuroendocrine (including carcinoid) tumours (NETs). Gut 2012, 61(1):6-32.

26. Garcia-Carbonero R, Salazar R, Sevilla I, Isla D: SEOM clinical guidelines for the diagnosis and treatment of gastroenteropancreatic neuroendocrine tumours (GEP NETS). Clin Transl Oncol 2011, 13(8):545-551.

27. Sun W, Lipsitz S, Catalano P, Mailliard JA, Haller DG, Eastern Cooperative Oncology G: Phase II/III study of doxorubicin with fluorouracil compared with streptozocin with fluorouracil or dacarbazine in the treatment of advanced carcinoid tumors: Eastern Cooperative Oncology Group Study E1281. J Clin Oncol 2005, 23(22):4897-4904.

28. Rinke A, Muller HH, Schade-Brittinger C, Klose KJ, Barth P, Wied M, Mayer C, Aminossadati B, Pape UF, Blaker M, Harder J, Arnold C, Gress T, Arnold R, Group PS: Placebo-controlled, double-blind, prospective, randomized study on the effect of octreotide LAR in the control of tumor growth in patients with metastatic neuroendocrine midgut tumors: a report from the PROMID Study Group. J Clin Oncol 2009, 27(28):4656-4663.

29. Raymond E, Dahan L, Raoul JL, Bang YJ, Borbath I, Lombard-Bohas C, Valle J, Metrakos P, Smith D, Vinik A, Chen JS, Horsch D, Hammel P, Wiedenmann B, 
Van Cutsem E, Patyna S, Lu DR, Blanckmeister C, Chao R, Ruszniewski P:

Sunitinib malate for the treatment of pancreatic neuroendocrine tumors. N Engl J Med 2011, 364(6):501-513.

30. Yao JC, Shah MH, Ito T, Bohas CL, Wolin EM, Van Cutsem E, Hobday TJ,

Okusaka T, Capdevila J, de Vries EG, Tomassetti P, Pavel ME, Hoosen S, Haas T, Lincy J, Lebwohl D, Oberg K, Rad001 in Advanced Neuroendocrine Tumors TTSG: Everolimus for advanced pancreatic neuroendocrine tumors. N Engl J Med 2011, 364(6):514-523.

31. Lim T, Lee J, Kim JJ, Lee JK, Lee KT, Kim YH, Kim KW, Kim S, Sohn TS, Choi DW, Choi SH, Chun HK, Lee WY, Kim KM, Jang KT, Park YS:

Gastroenteropancreatic neuroendocrine tumors: incidence and treatment outcome in a single institution in Korea. Asia Pac J Clin Oncol 2011, 7(3):293-299.

32. Li AF, Hsu CY, Li A, Tai LC, Liang WY, Li WY, Tsay SH, Chen JY: A 35-year retrospective study of carcinoid tumors in Taiwan: differences in distribution with a high probability of associated second primary malignancies. Cancer 2008, 112(2):274-283.

33. Yao JC, Phan AT, Chang DZ, Wolff RA, Hess K, Gupta S, Jacobs C, Mares JE, Landgraf AN, Rashid A, Meric-Bernstam F: Efficacy of RAD001 (everolimus) and octreotide LAR in advanced low- to intermediate-grade neuroendocrine tumors: results of a phase II study. J Clin Oncol 2008, 26(26):4311-4318.

doi:10.1186/1472-6823-14-54

Cite this article as: Zhang et al:: Clinical, pathological and prognostic characteristics of gastroenteropancreatic neuroendocrine neoplasms in China: a retrospective study. BMC Endocrine Disorders 2014 14:54.

\section{Submit your next manuscript to BioMed Central and take full advantage of:}

- Convenient online submission

- Thorough peer review

- No space constraints or color figure charges

- Immediate publication on acceptance

- Inclusion in PubMed, CAS, Scopus and Google Scholar

- Research which is freely available for redistribution 